\section{Slow Wave Activity}

Helga Peter

Marburg, Deutschland

\section{Synonyme}

SWA

\section{Definition}

Aktivität im Deltaband. Siehe auch

- „Elektroenzephalogramm“

- „Polysomnographie und Hypnogramm“ 